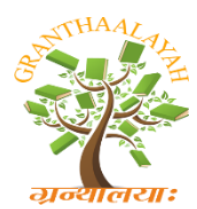

\author{
INTERNATIONAL JOURNAL OF R
GRANTHAALAYAH \\ A knowledge Repository
}

Science

\title{
COMPARATIVE ANALYSIS OF THE IMPACT OF LIBRAS ON DEVELOPMENT OF THE DEAF: A CASE STUDY IN A CITY IN NORTHEASTERN BRAZIL
}

\author{
Patrícia Teixeira de Matos ${ }^{\mathbf{1}}$, Giovana Maria Belem Falcāo ${ }^{\mathbf{1}}$, Pedro Claesen Dutra Silva ${ }^{\mathbf{1}}$, \\ Tania Maria De Sousa França ${ }^{1}$, Márcia Machado Marinho ${ }^{* 2}$, Gabrielle Silva Marinho ${ }^{1}$ \\ ${ }^{1}$ Pedagogy Course, State University of Ceará -FECLI / UECE, Brazil \\ *2 Department of Clinical and Toxicological Analysis, Federal University of Ceará, Brazil
}

\begin{abstract}
Currently, 9.7 million people in Brazil have some hearing impairment, who use a sign-visual language to communicate, the Brazilian Sign Language (LIBRAS). The discussion about education in an inclusive perspective of the deaf and Brazilian Sign Language has been expanded in recent years by education professionals, as well as by the deaf community itself. In this context, the present study sought to analyze the impact of the Brazilian Sign Language on the development of the deaf in the city of Acopiara-CE, located in the semiarid region of northeastern Brazil, through a case study structured in a descriptive and exploratory research. Data collection was carried out in three stages: visiting the deaf and his family, to explain the study, applying an identification questionnaire and applying a fundamental level I test. Thus, it was possible to analyze the reality of two deaf subjects, residents of the same city, approximate age range, who had their school journey diverging from each other, in which the mastery of the Brazilian Sign Language allowed a greater evolution in the inclusive process of one of the individuals. In conclusion, it was observed that inclusive education is still a subject of discussion, but proficiency in LIBRAS is fundamental to the inclusive process of the deaf.
\end{abstract}

Keywords: Brazilian Sign Language; Learning; Northeastern Brazil; Inclusive Education.

Cite This Article: Patrícia Teixeira de Matos, Giovana Maria Belem Falcāo, Pedro Claesen Dutra Silva, Tania Maria De Sousa França, Márcia Machado Marinho, and Gabrielle Silva Marinho. (2020). "COMPARATIVE ANALYSIS OF THE IMPACT OF LIBRAS ON DEVELOPMENT OF THE DEAF: A CASE STUDY IN A CITY IN NORTHEASTERN BRAZIL.” International Journal of Research - Granthaalayah, 8(2), 72-83. 10.29121/granthaalayah.v8.i2.2020.186.

\section{Introduction}

In Brazil, there are approximately 10 million deaf people, but 2.7 million still do not know the Portuguese language, an expressive number that arouses care and attention[1]. The Brazilian Sign Language was recognized in Brazil, as a legal means of communication and expression, in 2002 
with the approval of Law 10.436 [2], opening the way for bilingual education and the acceptance of the existence of a deaf culture, adopting LIBRAS (Figure 1) as the official language of the deaf community. This law was regulated by Decree No. 5,626 of December 22, 2005[3], which in its art. $3, \S 1$ and 2, chapter II, guides on the inclusion of LIBRAS as a mandatory subject in all undergraduate courses, in the various areas of knowledge, and optional in other courses in higher and professional education[4]

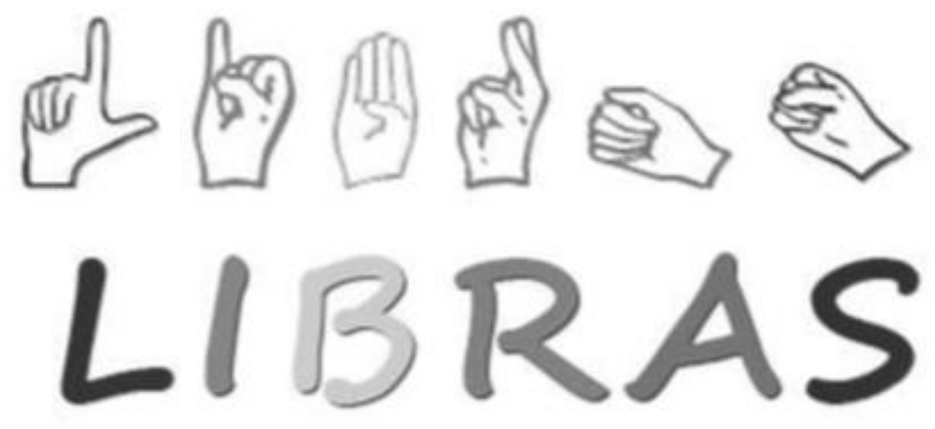

Figure 1: Brazilian Sign Language

In the last decades, the theme of education in an inclusive perspective has been widely discussed worldwide, with the aim of promoting the effective guarantee of equal rights, with emphasis on the right of all human beings to education. Regardless of physical, intellectual, gender, ethnic and cultural diversity, this movement aspires to a teaching concept that provides a transformation of human coexistence, based on valuing differences and equal opportunities for all humans[5][6].

This was evidenced through several events that marked the advance in formal education for people who have some type of disability, in particular the World Conference on Education for All that happened in the year 1990 in Thailand, in order to create mechanisms that could contemplate the all without distinction. As regards special education, it is reported in Article 3: "The basic learning needs of people with disabilities require special attention. It is necessary to take measures to guarantee equal access to education for people with any type of disability, as an integral part of the education system "[4].

Another important milestone was the Salamanca Declaration in 1994, which also contributed to the history of education, especially education for people with special educational needs, with the goal of including all children in mainstream education, whether they have special needs or not. In Brazil, the inclusion theme begins to take new directions through the current Constitution (1988), which states that all Brazilians have the right to education, as well as with the creation of Law No. 9,394 / 96, the National Education Guidelines and Bases Law (LDBEM), which guarantees free specialized educational assistance to students with special needs, preferably in the regular school system[4].

Law $n^{\circ} .8,069$, of July 13, 1990, which provides for the Statute of Children and Adolescents (ECA), establishes, in Chapter IV, in Article 53, the right to Education, Culture, Sport and Leisure, which: " [...] children and adolescents have the right to education, aiming at the full development of their person, preparation for the exercise of citizenship and qualification for work, guaranteeing them equal conditions for access and stay in school[7]. However, It was understood that even with so 
many advances in the educational field in our country, the need for changes is noticeable, especially with regard to the Education of the Deaf, which is a topic that still generates many discourses, due to the fact that it presupposes not only access to education, it implies a true transformation of culture, practices and policies in force in education systems, in order to guarantee the adaptation and appreciation of deaf culture, which transcends the use of a language other than the community of hearing people[8].

Given the above, this paper seeks to discuss the context of deaf education in the city of Acopiara, located in the Center-South region of the state of Ceará-BRAZIL. Focusing on knowing the educational process of two deaf people, the research proposes to study the trajectory of deaf education in the world and in Brazil, in which it will be emphasize.

In this perspective, the main objective of this study is to make an analysis of the impact of LIBRAS in the inclusion of the deaf in the reality of Acopiara-CE. Therefore, it was list the following specific objectives: (i) Equate language development versus learning; (ii) Understand the level of social interaction provided by the acquisition of LIBRAS; (iii) Reflect on the preparation to reach adult life.

To this end, an approach to education will be made, aimed at the person with deafness, from ancient times to the present day, and in the opportunity, it will be analyzed the case of two deaf people with very close ages, and who had different educational opportunities from each other and how it influenced each other's lives.

\section{Literature Review}

\section{Deafness in Brazil: History, Context and Conceptions}

Law No. 5,296 / 04 defines Hearing Impairment “[...] bilateral, partial or total loss, of forty-one decibels $(\mathrm{dB})$ or more, as evidenced by an audiogram in the frequencies of 500 hertz, and 2,000 hertz" [9].The child with deafness can present problems such as, for example, not speaking, feeling lonely, but the fact that he does not listen does not impair his intellectual capacity or his learning, but it can be considered that the learning process of the deaf child it is different from the listening child. Throughout the history of the deaf, analyzing from the beginning, it was saw that they were excluded from society simply because they did not listen. They had no right to attend the same places as other people, as they were also deprived of education, that is, they could not study and could not marry either[10].

Deaf education in Brazil began around 1855, during the second empire, with the arrival of Professor Hernest Huet, who was deaf and had studied at the Paris Institute. He came at the invitation of Emperor Dom Pedro II, to work with deaf children and brought with him the French manual alphabet and the French Sign Language. Giving rise to the Brazilian Sign Language.

On September 26, 1857 the institution was founded, which at the time was called the institute of the deaf and dumb, welcomed deaf people from all over the country, but only male, currently known as the National Institute of Deaf Education (INES), located in Rio de Janeiro[11]. 
Among those who were in charge of the institute as a director, it can be highlighted the doctor Tobias Leite, who in the educational process of the deaf gave priority to their professionalization, as he said that the deaf are faithful in carrying out the instructions and order of the boss.

Dr. Armando Paiva brings the issue of orality as the best way of learning for the deaf once again. In this management, students were subjected to test applications to verify the level of intelligence and aptitude for orality. According to the test results, students were separated by level of ability. The intention of the management with this separation was for the rooms to be homogeneous within the classification: complete deaf and dumb, incomplete deaf, semi-deaf [11].

Only after almost 100 years of existence of the institute of the Deaf, an education professional assumes the directorship of the aforementioned teaching division, Professor Ana Rímoli de Faria Dória. Who implemented during her term of office the normal teacher training course for the deaf. The course lasted three years and the Institute received professors from all over the country.

Years later, more precisely in the 1970s, Ivete Vasconcelos, deaf educator at the University of Gallaudet, arrived in Brazil for a visit, who brought with her the philosophy of total communication. And in the 1980s, bilingualism began to be propagated through the studies of professor Lucinda Ferreira Brito on the Brazilian Sign Language and research by professor Eulalia Fernandes on education of the deaf[9].

Other schools were important in the educational process of deaf people in Brazil, it can be highlighted the Instituto Santa Terezinha, founded in Campinas in 1929 and soon afterwards in 1933 it was transferred to São Paulo. Initially the Institute received only deaf girls and from 1970 onwards it started to accept deaf boys also working with the concept of integration in regular education[5]. Another important institution in this educational process for people with deafness is Instituto Educacional São Paulo o (IESP), founded in 1954, which in 1969 was donated to the Pontifical Catholic University of São Paulo (PUC / SP) becoming a reference in research and studies aimed at deaf people[4][7].

\section{Libras}

It is known that LIBRAS, in order to be recognized as the mother tongue of the hearing impaired, has made a great path from segregation to oppositions of inhumane methods towards the deaf, where they were excluded and marginalized by society[4][9].

"Libras is the acronym used to designate the Brazilian sign language, since each country has its own language, which expresses the cultural elements of that deaf community. It is used by the Brazilian deaf community, mainly in urban centers, because often the deaf who live in different locations and in rural areas end up for not knowing it and, thus, they end up developing their own gestural communication system, restricted to everyday situations and experiences[12]. There are also some deaf people who live in large cities who are unaware of sign language due to numerous factors or not being accepted by the family, lack of contact with other deaf people who use the technological option of school where he was educated, among other aspects "[13]. 
The sign language has its own grammatical structures, the deaf have their own grammatical structures, being composed of linguistic, phonological, morphological, semantic and syntactic levels, however it varies according to each culture. spatial, which, for it to be understood, depends on the skill of the hands and the visual perception to execute the movements with precision, as it can be see in its alphabet (figure 2) [13] [7].

Sign Languages increase their vocabularies with new signs introduced by deaf communities in response to cultural and technological changes[10][14]. A new sign appears with each need and, as long as it becomes accepted, it will be used by the community. The signals are formed from parameters[15], such as the combination of the movement of the hands with a certain shape in a given place, which may be a part of the body or a space in front of the body[13].

The Sign Language parameters are:

- Hands configuration: these are the shapes of the hands, which can be typing (manual alphabet) or other shapes made by the predominant hand or by the two hands of the emitter or signaler.

- There are an average of 64 different hand configurations.

- Point of Articulation: it is the place where the predominant hand configured,

- being able to touch some part of the body or be in a neutral vertical space (from the middle

- body to the head) and horizontal (in front of the emitter).

- Movement: the signs can have a movement or not.

- Orientation and Directionality: the signals have a direction in relation to the parameter ready mentioned. They will not be correct if this orientation and direction are changed in the realization of signals.

- Facial and / or Body Expression: many signs, in addition to the four parameters mentioned, I $\mathrm{n}$ its configuration, facial and / or body expression is a differentiating feature, whether it is a shoulder game, or expressions of joy, doubt or sadness that will give meaning and fluency to the signs.

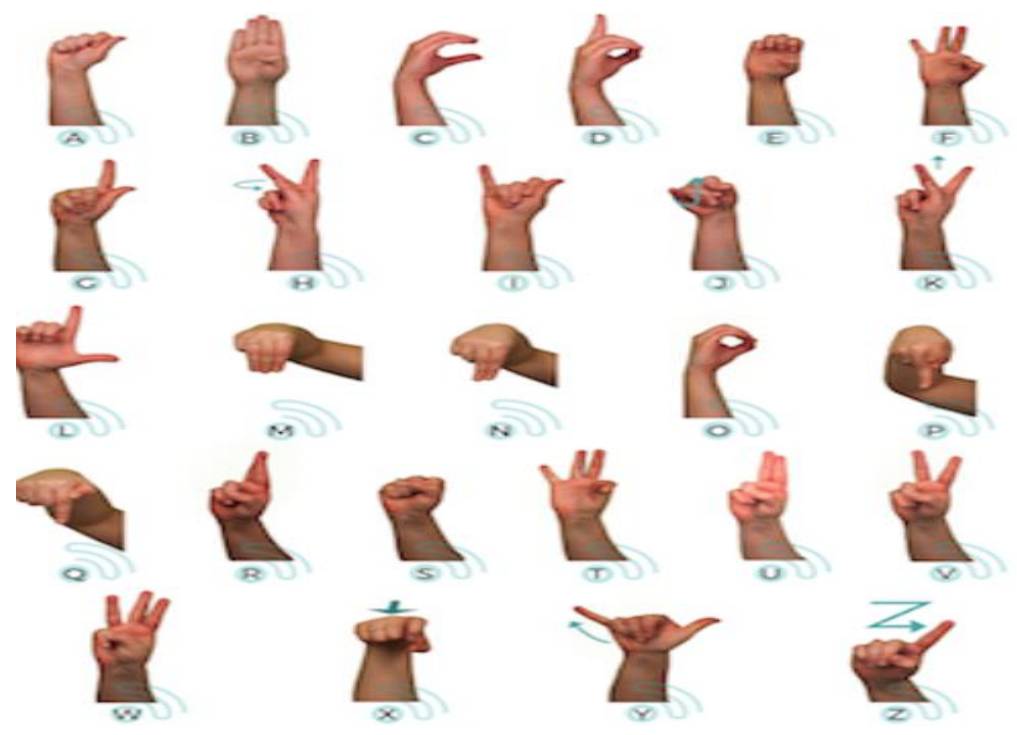

Figure 2: Alphabet in LIBRAS

source: adapted of https://conteudos.surdoparasurdo.com.br/alfabeto-em-libras-pdf 


\section{Research Methods}

Considering that the present work is a singular case study [16] that implies a particular and deep attention in order to capture the holistic and significant characteristics of a case. Experience of a student whose limited proficiency in the native language and its reflexes in learning, his methodology is structured in a descriptive and exploratory research, addressing the qualitative points. To this end, Martins and Theóphilo [17]emphasize that the case study is a qualitative assessment since it aims to study a social fact. Still with the thought of the mentioned authors, the case study:

It is an empirical investigation that investigates phenomena within their real context (naturalistic research), where the researcher has no control over events and variables, seeking to learn the totality of a situation and, creatively, describe, understand and interpret the complexity of a concrete case [17].

The case study is configured as situations arising from the common daily life clearly defined through specificities and contexts[15]. And with regard to exploratory research, the author reports: Developed with the objective of providing an overview, of an approximate type, about a certain fact. This type of research is carried out especially when the chosen theme is little explored and it is difficult to formulate precise and operable hypotheses [16].

Parallel to this, it has highlighted a descriptive research in which its objective is to describe the characteristics of the phenomenon under study. Descriptive research when in partnership with exploratory research becomes the most used among researchers who are concerned with practical performance [16].For Marconi and Lakatos [18], "Indicative and descriptive- when referring to the most important parts, components of the text. It uses short phrases, each corresponding to an important element of the work".

It is also important to highlight that the descriptive research refers to the development of the stages. And on this aspect Gil [16]highlights:

Research of this type has as its primary objective the description of the characteristics of a given population or phenomenon or the establishment of relationships between variables. There are countless studies that can be classified under this title and one of its most significant characteristics is the use of standardized data collection techniques.

In view of the current conjuncture of the Brazilian educational system, this research aims to analyze and compare two deaf residents in the municipality of Acopiara, state of Ceará. To this end, the work was developed with the deaf and their families, in which one of the deaf lives in the urban area of the city and the other in the rural area.

\section{Research Process}

As a result, in order to carry out the aforementioned research, it has sought a dialogue with the study participants, two deaf, for their consent in their participation in this work. Thereafter, a bibliographic survey is carried out, to then prepare the questionnaires to be applied with the 
participants. For data collection, a visit was made to the two families of the deaf participating in the research. Consequently, the application of the instruments relevant to the research was divided into two parts.

The first is an identification questionnaire, for knowledge of the life history and school trajectory of both involved in the study. The second is a fundamental level test: "PROVINHA BRASIL" ( Brazilian national assessment) evaluating literacy for 2 nd year students.

As already mentioned, data collection was carried out in 3 stages: visiting the family and the deaf, on this occasion, the student was presented and explained the study to be developed, and all agreed, the deaf signed the informed consent form. . After confirmation of the participants and their families to collaborate with this research, it has scheduled an upcoming meeting to apply the first questionnaire. In the application of this instrument, it was possible to identify and observe a lot, especially with the deaf $\mathrm{A}$, since this observation has been happening over time and family experience.

To obtain the information of the deaf A, it has applied the first questionnaire, with the participant's mother, since he does not know how to read and does not communicate through LIBRAS.

\section{Results and Discussions}

The responses to the questionnaire tell us that this individual is 33 years old, was born on August 25,1986 and is male. He lives in the countryside, $24 \mathrm{~km}$ away from the headquarters of the city, is the son of farmers, is the only deaf of the 4 children and his parents are also listeners, he is single and lives with his parents in his own residence. To move to the city or any other location, he uses his motorcycle, as he knows how to drive the vehicle as well as how to drive a car.

However, in his report, the participant's mother said it was risky, since the individual does not have a national driver's license. And in this regard, he feels sad, because it is one of the things he still achieved by not being a sign language user. His level of education is elementary school II, but, reports the mother that he did not have an interpreter in the classroom, she said: "because at that time we did not even know the existence of a language specific to the deaf". He says that in the classroom, the teachers spoke to the listening students and he just copied the content. On test days, the teacher placed the deaf with another student and everything that student put as an answer in his test, the deaf A, also put. According to the mother, his school trajectory was not easy, because most of the people who made up the school, did not understand his gestures. But although he does not know LIBRAS and has not learned Portuguese, he is cheerful and fun, likes to go out with friends, meet people and at leisure, at home, likes to draw, enlarging images.

The mother also said that he has the dream of taking the national driver's license, but is afraid of not being able to learn Libras because of his age. As he lives in the rural area of the municipality, he follows the same profession as his father: Farmer. The mother reports that he does not like it very much, because it is hard work, but it is the only way to earn a little money in that location, since the family income is received from the "Bolsa Família"( Brazilian government's anti-poverty social assistance program) and crop guarantee programs (this when proven that there was no enough winter to purchase food from the plantation). 
And in relation to the family culture, the mother explains that reading magazines and books sometimes, she is not in the habit of traveling and according to her: "we are neither in the habit nor able to travel", they never went to the cinema, they don't have the habit of listening to music and do not play sports. But she says that the family is very close and they like to be together, that she only regrets one thing: that she gave up her deaf son when he was a child for her mother-inlaw to take care of. She said: "we had no conditions and my son didn't listen, so I gave it to his grandmother, but she didn't want to because she didn't want to take on the responsibility that was mine and the father's and even then my son was raised by her, because he the day at her house and came home I just slept. On the one hand I am sorry, on the other hand, I am happy because he had everything that my father and I could not offer at that time".

The mother also said that her son got a hearing aid, but he used it for a short time, because he did not adapt, he gestured to the family that the device only brought a loud noise and he did not understand anything.

In return, the Deaf B participant in our research is the one who answers the questionnaire, with the help of the interpreter $\mathrm{X}$, who is a pedagogue and has a postgraduate degree in Libras. In his account he tells the interpreter that he is 29 years old, was born on August 21, 1990 and is male, lives in the Aroeiras neighborhood, close to the city center, is the second child, is the only deaf and is single. His parents are retired and he also receives a salary, and in a report he says he lives in his own home with his grandmother who is also retired.

He owns a motorcycle that uses it to get around the city, he says carefully, since he does not have a national driver's license.

He finished high school and now he's fine, he says. But he intends to study because he wants to be a police officer. He communicates with everyone through Sign Language, "but when someone doesn't understand, he communicates through the gestures lol". Report. He likes to participate in events and movements that involve the deaf community, so he interacts with other deaf people. However, he says that it was not easy, to get there, because according to him, as a child he also went to school just to be in a classroom, since the teachers did not care about his learning. However, perhaps because he lived in the city, at the age of 11 , he had his first contact with LIBRAS and as he was impressed, he decided to learn more and take ownership of what was making him learn.

But he says that nothing was easy because he did not have an interpreter to help him, and studied until elementary school II, with the help of two teachers who knew the basics of Sign Language. But he was always looking to study and get to know LIBRAS. He arrived at high school and had the help of an interpreter, but he felt difficulties in the subjects, mainly English.

He also communicates through social networks, he has WhatsApp and Facebook and interacts with deaf friends through the applications, both on the mobile device and on the computer. He likes to travel, meet people and flirt, he says. Practices sports such as: Capoeira and football. At the weekend he participates in the mass, but reports: "it is only boring because there is hardly anyone who can interpret the mass for me, but I still like to go". 
Regarding family culture, he says that his sister, who is married, is a teacher and always liked to read magazines, books, listen to music, never went to the cinema because the city does not offer this entertainment, but she has already participated in FETAC (Acopiara Theater Festival)), which takes place at the city's Social Center. Although he does not live with his parents, they are united and are afraid of losing them.

With the identification of the participants in our study, it has scheduled an upcoming meeting for the application of the second instrumental: Provinha Brasil, which consists of 20 Portuguese questions with level for elementary I.

When presenting the evidence to the deaf A, he looked at his mother smiled and shook his head, as if to say that he will not be able to solve it, but he accepted. And then he started to answer and in 15 minutes he was done. When analyzing his answers, we saw that he got 2 hits out of 20 questions.

By talking to the participant's mother, it can be understand why deaf A answered 20 Portuguese questions so quickly. She says: "good as at school he only copied and tested with another colleague, he just checked the ones he thought was correct and got these two questions right because their answer was explicit in the statement of the question itself".

The same test was applied to deaf B, who, unlike deaf A, needed 1 hour and 40 minutes to resolve the 20 questions. We again had the help of the interpreter $\mathrm{X}$, who interpreted the question for the deaf $\mathrm{B}$ and helped him when he had doubts about the answer, but without saying the correct option for each question.

After the test, it has analyzed the answers and detected 15 correct answers out of 20 questions. Talking to the interpreter, the same reports that he is very intelligent and the questions he didn't get right were text interpretation, and it really is a little more difficult for them, you need to have a lot of knowledge of Portuguese, she says and adds: "But in overall he did very well in that race ".

Analyzing the educational environment today, it can be see a significant advance in terms of inclusive education, but it is also noticeable that there is still something to be done to improve the quality of education in this context.

Brazil has legal support that ensures quality education for all without distinction, but school spaces still need improvements so that, in fact, inclusion happens.

In this context, the results of this research emerge, which brings a comparative educational analysis of 2 deaf individuals, living in the same city, close ages, but distinguished by access to LIBRAS. Table 1 shows the characterization data of the participants who collaborated with this work.

Table 1: Characterization of the participants who collaborated with this work

\begin{tabular}{|l|l|l|}
\hline Descriptor & Deaf A & Deaf B \\
\hline Age & 33 Years Old & 29 Years Old \\
\hline Age That Identified Deafness & 6 Months & 1 Year \\
\hline Origin of Deafness & Congenital & Congenital \\
\hline
\end{tabular}




\begin{tabular}{|l|l|l|}
\hline Libras User & Not & Yes \\
\hline Schooling & Elementary School I & High School \\
\hline Family Use of Libras & Not & Little \\
\hline Communication with The Family & Gestures & Gestures /Libras \\
\hline First Contact with Libras & 33 Years Old & 11 Years Old \\
\hline
\end{tabular}

After applying the instruments already mentioned, it has realized the educational difference between those involved. The deaf A: He recently met and does not use the Brazilian Sign Language and to answer the questionnaires, we count on the help of his mother, who understands everything that he gesticulates. In this context Nader [19] reports:

If the home sign language, on the one hand, can play some linguistic-cognitive situations, on the other hand, it is limited to deal with more complex contents and allow the learning of more abstract concepts[19].

In view of this, Deaf A: answered a test that consisted of 20 questions of which he obtained 2 correct answers and that because, according to his mother, he knows how to copy and the questions that he was successful, the answers were in the statement of the question. The other identification tool was answered by the participant's mother.

Regarding the communication of deaf individuals in the family, Fernandes [20]says that the deaf's homemade gestures can contribute to language training and still allow their cognitive development. Deaf B: answered the 2 questionnaires, he has completed high school and with the help of the interpreter X, answered the 2 instrumentals. Obtaining 15 correct answers in the resolution of the same test passed to the other deaf subject.

Throughout the research, through the instruments and the collaboration of the family of the deaf, we could see that, although the deaf A, does not know and does not use LIBRAS, he finds other ways of communicating with other people.

Returning to the concepts of [9] it is important that the deaf have their form of communication in the family environment, however this is not enough to deal with more complete subjects, given that sign language does not have the structure of a natural language.

In this way, it has identify the discouragement of the subject in question of continuing his studies, since he points out that because of his age, he will not learn the mother tongue of the deaf community (LIBRAS). That other deaf people learn when they are small and he is already an adult. Subsequent to this analysis, she spoke with the mother of the aforementioned deaf person and she points out that he stopped studying in elementary school II of his own free will, because according to him he would not be able to absorb the contents since the teachers gave classes to the students. listening students and he was in the classroom just to be there and copy what his colleagues did. And that I would never get a good job, because people do not hire deaf people and especially those who do not know how to communicate using their own language.

On the other hand, the deaf B finished high school, knows how to read, participates in events involving the theme of inclusive education and interacts with other deaf users of the Brazilian Sign 
Language, the family knows a little about Sign Language, but not yet enough for total communication in LIBRAS with that deaf person, using sign language as well as the family of the deaf person. Participates in courses in LIBRAS, is invited to tell about his school trajectory and the learning of Sign Language.

Continuing with the analysis, it is worth highlighting the significant role of both the family and the school unit, for the development of the deaf individual, since one complements the other. Which leads it to reflect on the acquisition of Sign Language by both participants.

\section{Conclusions}

In conclusion, it can be said that the production of this work was a long way of learning and reflection and, when studying the two individuals and their trajectories of school life, it could observe that inclusive education is still a subject of discussion in the Brazilian reality, as it does not it happens as it should with regard to the education of the deaf.

Therefore, it is worth thinking what can be done so that this reality takes positive directions in relation to the learning of these subjects, in the perspective of an inclusive school with these students in a regular classroom.

Legislation is well known, which in theory points out that this is possible, and so it is worth emphasizing and questioning whether in practice the school unit has the necessary subsidies so that the learning of the deaf is satisfactory.

In view of the above, it has saw the reality of two deaf individuals, who had their school journey diverging from each other, perhaps due to lack of communication, difficulty in access or lack of information and even interest, but the legislation is the same for everyone, and so it is up to us future teachers to ask questions about compliance with educational laws aimed at deaf people and act so that, in fact, inclusion happens in our reality.

\section{Acknowledgements}

The present work was partially funded by $\mathrm{CNPq}$ - National Council for Scientific and Technological Development and CAPES - Brazilian Federal Agency for Support and Evaluation of Postgraduate Education of the Brazilian Ministry of Education.

\section{References}

[1] J. Schimiguel, R. F. Fernandes, and L. dos S. França, "Development of learning objects in the form of games for teaching pounds," IV Simpósio Nac. Ensino Ciência e Tecnol., p. 12, 2014.

[2] C. de M. M. Costa, M. M. Marinho, and G. S. Marinho, "M-Learning in Teaching Pounds: Assessment of Learning Objects," Rev. Expressão Católica, vol. 6, no. 1, p. 28, 2018.

[3] E. Santos et al., "XVI ENDIPE - National Meeting of Didactics and Teaching Practices UNICAMP - Campinas - 2012 22," Rev. Incl., vol. 3, no. Cm, pp. 1-25, 2016.

[4] A. de O. GIANOTTO, "Teaching the Brazilian Sign Language (Libras) as a Factor of Local Development in Territorial Contexts," p. 91, 2016. 
[5] D. V. C. Sousa, Listening Children In The Context Of Inclusive Regular Schools Dissertation submitted to the Postgraduate Program in Linguistics at the Federal University of Santa Catarina to obtain the Degree of Arantes Leite Florianópolis Identification sheet of the work prepared by the author, through the Automatic Generation Program of the UFSC University Library .," 2017.

[6] M. Strong and P. M. Prinz, "A Study of the Relationship Between American Sign Language and English Literacy,” J. Deaf Stud. Deaf Educ., 1997.

[7] K. E. A. C. Viana, "Educação Especial: O Ensino De Libras Mediado Por Novas Tecnoligias.," II CONEDU - Congr. Nac. Educ., 2015.

[8] D. DeWitt, N. Alias, Z. Ibrahim, N. K. Shing, and S. M. M. Rashid, "Design of a Learning Module for the Deaf in a Higher Education Institution Using Padlet," Procedia - Soc. Behav. Sci., 2015.

[9] A. I. Da, L. Para, I. Escolar, D. O. Surdo, D. Marilene, and V. A. Meyer, "Palavra chave : Inclusão, LIBRAS , Formação Docente .

[10] M. Marschark and P. C. Hauser, Deaf cognition: Foundations and outcomes. 2008.

[11] P. S. Ribeiro Rocha, R. W. De Lima, and P. G. G. Queiroz, "Technologies for teaching the Brazilian Sign Language (LIBRAS): A systematic review of the literature,” Rev. Bras. Informática na Educ., vol. 26, no. 3, p. 42, 2018.

[12] A. Luiza et al., "Web - Revista SOCIODIALETO” Rev. Incl., vol. 7, no. 2, pp. 276-283, 2017.

[13] L. A. Fernandes, "Sistema brasileiro de escrita das línguas de sinais : conhecendo o sistema ELiS. 2017."

[14] A. M. Lieberman, M. Hatrak, and R. I. Mayberry, "Learning to Look for Language: Development of Joint Attention in Young Deaf Children," Lang. Learn. Dev., 2014.

[15] C. J. Evans, "Literacy development in deaf students: Case studies in bilingual teaching and learning," Am. Ann. Deaf, 2004.

[16] R. K. YIN, . "Estudo de caso. Planejamento e métodos," Porto Alegre: Artmed, Ed. 2002.

[17] C. R. MARTINS, Gilberto de Andrade; THEÓPHILO, Metodologia da Investigação científica para ciências sociais aplicadas. 2007.

[18] M. Marconi and E. Lakatos, "Fundamentos de metodologia científica," Ed. Atlas S. A., 2003.

[19] J. M. V. Nader, "Late language acquisition and its effects on the cognitive development of the deafs," Universidade Estadual de Campinas. Instituto de Estudos da Linguagem, 2011.

[20] S. Fernandes and L. C. Moreira, "Políticas de educação bilíngue para surdos: o contexto brasileiro," Educ. em Rev., 2014.

*Corresponding author.

E-mail address: marcia.marinho @uece.br 